\title{
Determination of Antioxidants in Oil Palm Empty Fruit Bunches
}

\author{
Ng Mei Han and Choo Yuen May \\ Engineering and Processing Research Division, Malaysian Palm Oil Board 6, \\ Persiaran Institusi, Bandar Baru Bangi, 43000 Kajang, Selangor, Malaysia \\ Received 2012-05-30, Revised 2012-09-05; Accepted 2012-09-05

\begin{abstract}
The oil palm Fresh Fruit Bunches (FFB) undergoes sterilization before being threshed to separate the fruits from the bunch. Upon threshing, the fruits were pressed for its oil while the now Empty Fruit Bunch (EFB) will be discarded or used as biomass. It is believed that the EFB contains small amount of oil as well as phytonutrients which contain antioxidative property. This study reports on the extraction and analyses of various types of phenolic compounds, which have been known to exhibit antioxidant property, from the EFB. Different methods were employed in order to extract the Soluble Free (SF), Insoluble Bound (ISB) and Esterified Free (EF) phenolics in the EFB. Analyses of these phenolics were carried out spectrophotometricaly. The concentrations of the SF, ISB and EF phenolics varies among the wet and dried EFB extracts. All the extracts from both wet and dried EFB exhibit radical scavenging activities.
\end{abstract}

Keywords: Palm, Fresh Fruit Bunches (FFB), Antioxidant, Phytonutrients, Empty Fruit Bunches (EFB)

\section{INTRODUCTION}

The oil palm fruits grow in bunches weighing in average 40-80 $\mathrm{kg}$ when fully ripe. These bunches are termed Fresh Fruit Bunches (FFB). When the fruits ripen, the FFB is harvested and sent to the palm oil mills for processing. At the palm oil mill, the FFB first undergo sterilization to halt the enzymatic lypolysis content and reduces the quality of the oil. The sterilized FFB then goes through a threshing process to separate the fruit nuts from the Empty Bunches (EFB). The fruit nuts were then pressed for its oil while the EFB, which consists of ca. $20-25 \%$ stalk and $75-80 \%$ spikelets is discarded or used as biomass.

The oil obtained from the pressing of the fruit nuts contains vast variety of phytonutrients, i.e., carotenes, tocopherols, tocotrienols, squalene, sterols and coenzyme Q (Goh et al., 1985; Ng et al., 2004; 2006; 2009; Choo et al., 2005). These phytonutrients have been found to exhibit beneficial properties such as anti cancer and antioxidative (Goh et al., 1994; Ong et al., 1995; Kagan and Quinn, 2001; Nesaretnam et al., 1992; 1995). The EFB on the other hand, contains small amount of oil and it is now believed that some of the phytonutrients found in the oil are retained in the EFB. A particular group of compounds that are of interest is the phenolics. which otherwise, will cause rises in the free fatty acids

The phenolics are water soluble and they have been found to be powerful antioxidants. They have been found to have potential applications as nutraceuticals and as cosmetics. Neo et al. (2008) and Sundram et al. (2003) reported the presence of the phenolics in the oil palm fruits in FFB. The sterilization process in the oil palm mill which uses steam has possibly caused the phenolics in FFB to be washed away with water and ended up in the Palm Oil Mill Effluent (POME) (Sambanthamurthi et al., 1998). Sambanthamurthi et al. (1998; 2007) and co-workers reported on found in the POME and developed a method to recover them from the sludge. Besides POME, the phenolics have also been found to be retained in the fibre of the oil palm fruits nuts after screw pressing (Lau et al., 2007). As such, it is not surprising if the phenolics are also found in the EFB. This study reports the extraction and analyses of various types of phenolics in EFB.

\section{MATERIALS AND METHODS}

\subsection{Chemicals and Apparatus}

All chemicals were purchased from Merck (Darmstadt, Germany). Standards of gallic acid, catechin, ferulic acid, rutin, 2,2-diphenyl-2picrylhydrazyl (DPPH) radical were purchased from Sigma Chemical Co. (St. Louis, MO, USA). All reagents Corresponding Author: Ng Mei Han, Malaysian Palm Oil Board 6, Persiaran Institusi, Bandar Baru Bangi, 43000 Kajang, Selangor, Malaysia 
used were of analytical grade unless otherwise stated. Spectrophotometric analyses were performed using a Thermo Spectronic Helios $\alpha$ UV-Visible spectrophotometer.

\subsection{Sample Preparation}

Empty Fruit Bunches (EFB) were obtained from the Malaysian Palm Oil Board Palm Oil Milling Technology Centre (POMTEC), in Negri Sembilan, Malaysia. The EFB collected were chopped and separated into two whereby one part was left to dried overnight in the oven of temperature not more than $60^{\circ} \mathrm{C}$. Both the fresh and dried EFB were subjected to the same deoiling process thereafter where the EFB were soaked overnight in hexane. The solvent was then filtered and the deoiled EFB were subjected to a series of extractions to extract the phenolics.

\subsection{Extraction of Soluble Free, Esterified and Insoluble-Bound Phenolic Compounds}

Extractions of different groups of phenolics from EFB were performed by adopting the method as described by Krygier et al. (1982) with few modifications. The deoiled EFB were extracted six times with methanol:acetone:water $(7: 7: 6, \quad \mathrm{v} / \mathrm{v} / \mathrm{v})$ at room temperature followed by concentration of the pool extracts by evaporation. Lipid contaminants in the mixture was removed by hexane after adjusting the $\mathrm{pH}$ of the mixture to 2 by $\mathrm{HCl}$. The Soluble Free (SF) phenolics in the mixture was extracted by using diethyl ether: ether acetate $(1: 1 . \mathrm{v} / \mathrm{v})$. Esterified Free (EF) phenolics in the aqueous fraction were hydrolysed with $4 \mathrm{M}$ $\mathrm{NaOH}$ for $20 \mathrm{~h}$ at room temperature under nitrogen blanketing. The resulting hydrolysate was then acidified o $\mathrm{pH} 2$. EF phenolics were obtained by extraction using diethyl ether: ethyl acetate $(1: 1, \mathrm{v} / \mathrm{v})$. The Insoluble Bound (ISB) phenolics were obtained from the deoiled EFB following extraction by methanol:acetone:water, hydrolyses with $\mathrm{NaOH}$ and extraction using diethyl ether: ethyl acetate. The SF, EF and ISB phenolics extracted were then redissolved in $\mathrm{MeOH}$ for subsequent analyses.

\subsection{Extraction of Total Phenolics}

Total phenolic compounds regardless of groups were extracted from the deoiled EFB according to the method described by Wang and Helliewel (2001) as well as Neo et al. (2008). The deoiled EFB was mixed with $40 \mathrm{~mL} 60 \%$ ethanol. Five milliliters of $6 \mathrm{M} \mathrm{HCl}$ was added to the mixture and refluxed for $2 \mathrm{~h}$. The cooled extract was then made up to $50 \mathrm{~mL}$ with $60 \%$ ethanol.

\subsection{Determination of Phenolics Indices}

The different types of phenolics extracted from the deoiled EFB were analysed by using a UV spectrophotometer. Bonoli et al. (2004) method for the determination of total phenolics was adopted. The extracts were diluted with methanol and UV absorbance at 280, 320 and $370 \mathrm{~nm}$ were recorded.

\subsection{Determination of Total Phenolics}

Total Phenolic Compounds (TPC) in the EFB were determined using the Folin-Ciocalteau method (Singleton and Rossi, 1965). $0.1 \mathrm{~mL}$ of the total phenolic extract was added with $0.5 \mathrm{~mL}$ FolinCiocalteau reagent, followed by $7 \mathrm{~mL}$ distilled water. The mixture was left standing at room temperature, in the dark for $5 \mathrm{~min}$. Thereafter, $1.5 \mathrm{~mL}$ sodium carbonate solution was addied and the mixture was left at room temperature for another $2 \mathrm{~h}$. UV absorbance at $765 \mathrm{~nm}$ was measured with gallic acid as reference.

\subsection{Determination of Total Flavonoids Content}

Liu et al. (2002) method for the determination of total flavonoids content was adopted. $0.5 \mathrm{~mL}$ extract was added with $2.5 \mathrm{~mL}$ distilled water, followed by $0.15 \mathrm{~mL}$ $5 \% \mathrm{NaNO}_{2}$ solution. The mixture was then left standing for $6 \mathrm{~min}$ at room temperature before adding in $0.3 \mathrm{~mL}$ $10 \% \mathrm{AlCl}_{3} \cdot 6 \mathrm{H}_{2} \mathrm{O}$ solution. The mixture was left to stand for a further $5 \mathrm{~min}$, added with $1 \mathrm{~mL} 1 \mathrm{M} \mathrm{NaOH}$ and made up to $5 \mathrm{~mL}$ with distilled water. The solution was vortexed and the UV absorbance at $510 \mathrm{~nm}$ was recorded with catechin as reference.

\subsection{DPPH Radical Scavenging Assay}

DPPH radical scavenging assay was carried out according to the method by Thaipong et al. (2006) and Yen and Duh (1994) with slight modifications. DPPH stock was prepared by dissolving $24 \mathrm{mg}$ DPPH in $100 \mathrm{~mL}$ methanol. The working solution contained $10 \mathrm{~mL}$ stock solution and $45 \mathrm{~mL}$ methanol. $0.15 \mathrm{~mL}$ extract was added to $2.85 \mathrm{~mL}$ DPPH working solution and left to react in the dark for 24 $\mathrm{h}$. The absorbance at $515 \mathrm{~nm}$ was measured.

\section{RESULTS}

The results from the analyses of phenolics in EFB was carried out by several hydrolytic procedures. Total Phenolic Compounds (TPC), Flavonol Indices (FI), Hyxroxycinnamic Acid Indices (HCAI), O-Diphenol Indices (ODPI) and Total Flavonoid Compounds (TFC) are depicted in Fig. 1-6.

The results of the radical scavenging activities of the different samples are depicted in Fig. 7. 
Ng Mei Han and Choo Yuen May / American Journal of Applied Sciences 9 (11) (2012) 1862-1867

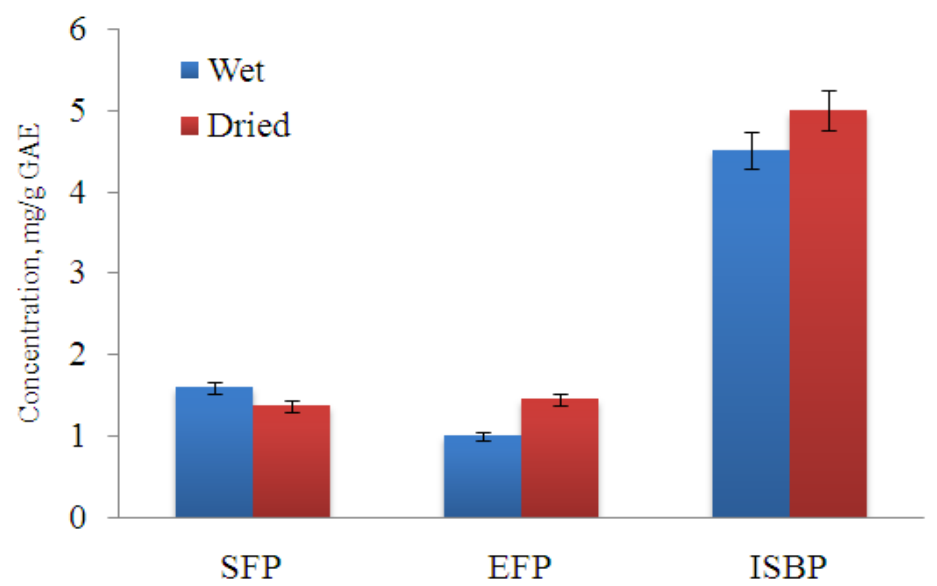

Fig. 1. Phenolic indices of empty fruit bunches extracts

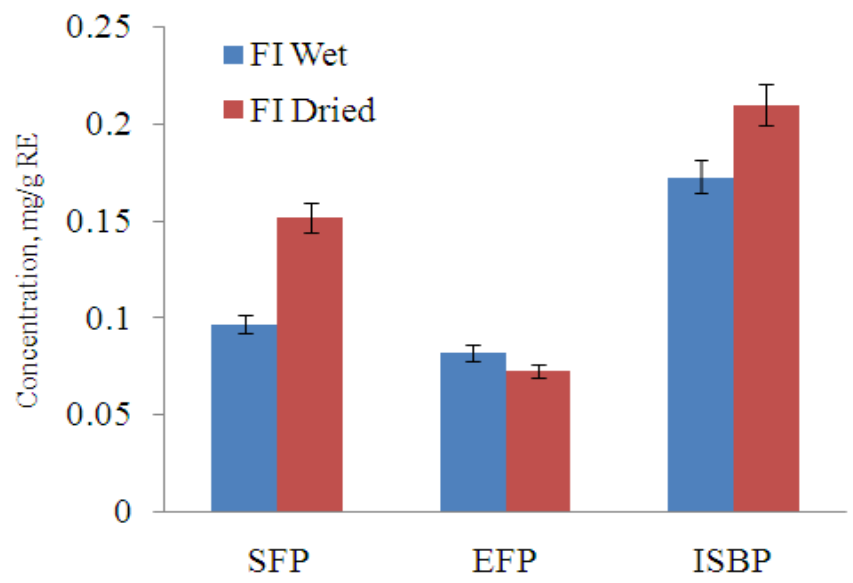

Fig. 2. Flavonol indices of empty fruit bunches extracts



Fig. 3. Total flavonoid content of empty fruit bunches extracts 
Ng Mei Han and Choo Yuen May / American Journal of Applied Sciences 9 (11) (2012) 1862-1867

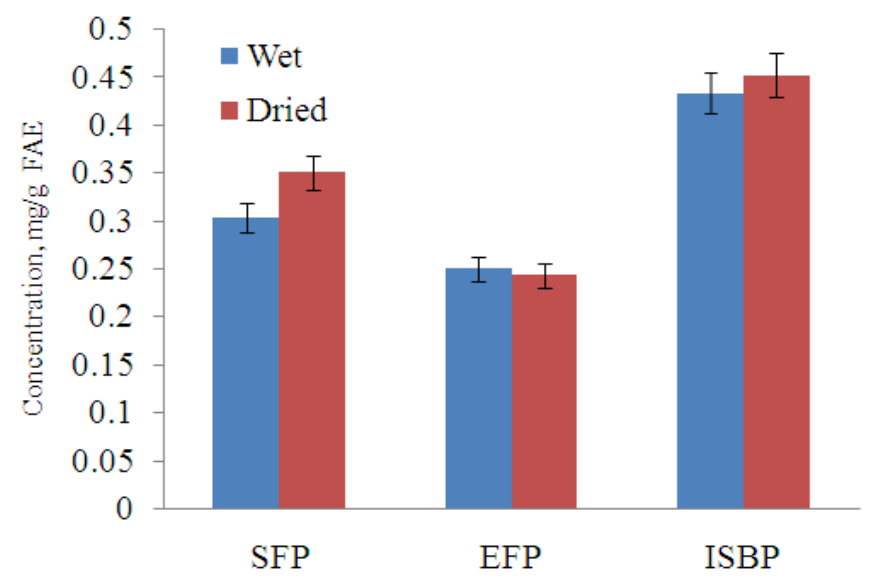

Fig. 4. Hydoxycinnamic acid indices of empty fruit bunches extracts

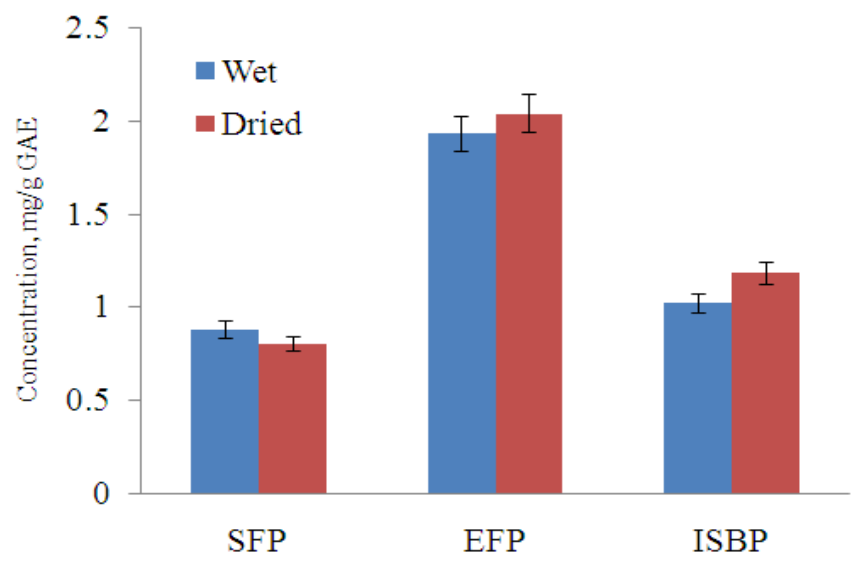

Fig. 5. o-Diphenol indices of empty fruit bunches extracts

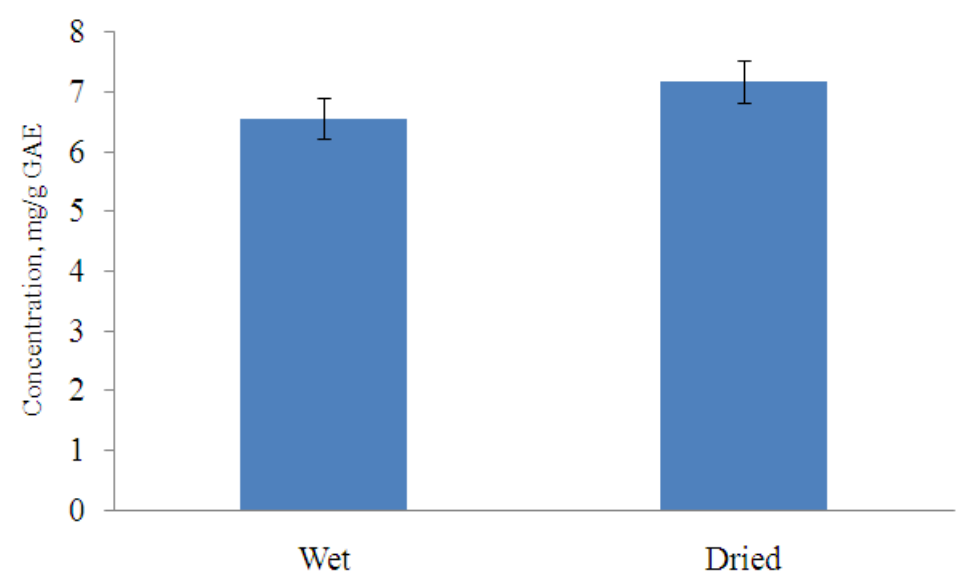

Fig. 6. Total phenolic content of empty fruit bunches extract 


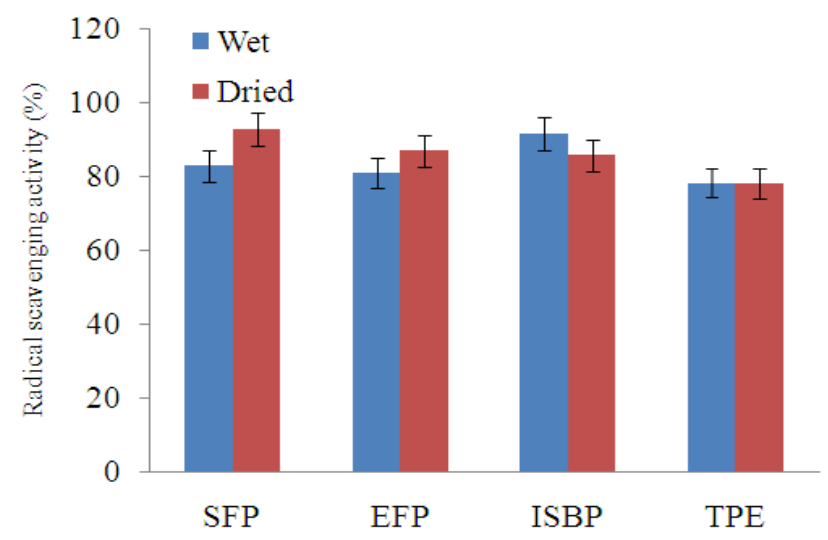

Fig. 7. DPPH radical scavenging activities of empty fruit bunches extracts

\section{DISCUSSION}

Quantification of phenolics in EFB was carried out by several hydrolytic procedures. Total Phenolic Compounds (TPC), Flavonol Indices (FI), Hyxroxycinnamic Acid Indices (HCAI), O-Diphenol Indices (ODPI) and Total Flavonoid Compounds (TFC) were quantified by measuring absorbance at different wavelengths. Each group of phenolic compounds was quantified with reference to a certain standard of the same group. TPC was quantified as Gallic Acid Equivalents (GAE), FI as Rutin Equivalent (RE), HCAI as Ferulic Acid Equivalents (FAE), ODPI as Gallic Acid Equivalents (GAE) and TFC as Catechin Equivalent (CE).

Each of the extracts (SF, EFP, ISBP) with the exception of TPE was subjected to different analyses to determine the type of phenolic compounds present. Each type of phenolics does not respond to the spectral analysis in the similar way. In this respect, ODPIs may provide more accurate analyses as it is carried out based on the reaction of a specific phenolic structure. Figure 1$\mathbf{6}$ depict the results from these analyses.

Generally, the dried EFB extracts showed higher concentrations of TPC. TPC is an indication of the amount of phenolics present regardless of their respective groups. The concentration of specific groups of the phenolics in EFB varies between the SFP, EFP and ISBP extracts.

The phenolic indices is higher in dried EFB compared to the wet ones in the EFP and ISBP extracts. However, different scenario is seen for the SFP extract. The Total Phenolic Extract (TPE) is considered to represent the Free and Bound (FB) phenolics present in EFB as it is extracted by reflux with acid. In this respect, the $\mathrm{FB}$ is the dominant form of phenolics in EFB, followed by ISBP, EFP and SFP. Although the TPE is able to give a general idea on the concentration of phenolics, the SFP, ISBP and EFP nevertheless, provided a more complete picture of the phenolic content in EFB. The flavonol indices of the SFP extract, amounting from $0.1-0.15 \mathrm{mg} \mathrm{g}^{-1}$ RAE showed that the flavonoid in SFP consists mainly of flavonols. The EFP and ISBP extracts however, do not show similar pattern.

All the extracts of both wet and dried EFB showed radical scavenging activity. The total phenolic extract showed similar radical scavenging activity between the wet and dried EFB. Similar scenario was detected for the EFP and SFP extracts. However, the opposite is true for the ISBP extract whereby the wet EFB showed higher radical scavenging activity than the dried EFB. The ISBP extracts for both the wet and dried EFB showed higher radical scavenging activity than the other extracts of the EFB. In general, the DPPH radical scavenging activities for the dried and wet EFB extracts followed the order of SFP $>$ EP $>$ ISBP $>$ TPE and ISBP $>$ SFP $>$ EFP $>$ TPE respectively.

\section{CONCLUSION}

The EFB contains various types of phenolic compounds which exhibit radical scavenging activities. Different methods need to be employed to extract the phenolics from the EFB and UV spectrophotometry is able to quantify these phenolics.

\section{REFERENCES}

Bonoli, M., V. Verardo, E. Marconi and M.F. Caboni, 2004. Antioxidant phenols in barley (Hordeum vulgare L.) flour: Comparative spectrophotometric study among extraction methods of free and bound phenolic compounds. J. Agric. Food Chem., 52: 5192-5200. PMID: 15291496 
Choo, Y.M., M.H. Ng, A.N. Ma, C.H. Chuah and M.A. Hashim, 2005. Application of supercritical fluid chromatography in the quantitative analysis of minor components (carotenes, vitamin E, sterols and squalene) from palm oil. Lipids, 40: 429-432. DOI: 10.1007/s1 1745-006-1400-6

Goh, S.H., N.F. Hew, A.E. Norhanom and M.C. Yadar, 1994. Inhibition of tumour promotion by various palm-oil tocotrienols. Int. J. Cancer, 57: 529-531. DOI: $10.1002 / \mathrm{ijc} .2910570415$

Goh, S.H., Y.M. Choo and A.S.H. Ong, 1985. Minor constituents of palm oil. J. Am. Oil Chem. Soc., 62: 237-240. DOI: 10.1007/BF02541384

Kagan, V.E. and P.J. Quinn, 2001. Coenzyme Q: Molecular Mechanisms in Health and Disease. 1st Edn., CRC Press, Boca Raton, FL., ISBN-10: 0849387329, pp: 390.

Krygier, K., F. Sosulski and L. Hogge, 1982. Free, esterified and insoluble-bound phenolic acids. 1. Extraction and purification procedure. J. Agric. Food Chem., 30: 330-334. DOI: 10.1021/jf00110a028

Lau, H.L.N., Y.M. Choo, A.N. Ma and C.H. Chuah, 2007. Extraction and identification of water soluble compounds in palm pressed fibre by $\mathrm{SC}-\mathrm{CO}_{2}$ and GC-MS. Am. J. Environ. Sci., 3: 54-59. DOI: 10.3844/ajessp.2007.54.59

Liu, M., X.Q. Li, C. Weber, C.Y. Lee and J. Brown et al., 2002. Antioxidant and antiproliferative activities of raspberries. J. Agric. Food Chem., 50: 2926-2930. DOI: $10.1021 /$ jf0111209

Neo, Y.P., A. Ariffin, C.P. Tan and Y.A. Tan, 2008. Determination of oil palm fruit phenolic compounds and their antioxidant activities using spectrophotometric methods. Int. J. Food Sci. Technol., 43: 1832-1837. DOI: 10.1111/j.13652621.2008.01717.x

Nesaretnam, K., H.T. Khor, J. Ganesan, Y.H. Chong and K. Sundram et al., 1992. The effect of vitamin E tocotrienols from palm oil on chemically induced mammary carcinogenesis in female rats. Nutr. Res., 12: 879-892. DOI: 10.1016/S0271-5317(05)80645-1

Nesaretnam, K., N. Guthrie, A.F. Chambers and K.K. Caroll, 1995. Effect of tocotrienols on the growth of a human breast cancer cell line in culture. Lipids, 30: 1139-1143. DOI: 10.1007/BF02536615
Ng, M.H., C.Y. May, M.A. Ngan, C.C. Hock and M.A. Hashim, 2004. Isolation of palm tocols using supercritical fluid chromatography. J. Chromatogr. Sci., 42: 536-539. PMID: 15768840

Ng, M.H., Y.M. Choo, A.N. Ma, C.H. Chuah and M.A. Hashim, 2006. Isolation and identification of individual palm carotenes using supercritical fluid chromatography. Malaysian J. Sci., 25: 139-145.

Ng, M.H., Y.M. Choo, A.N. Ma, C.H. Chuah and M.A. Hashim, 2009. Determination of coenzyme $\mathrm{Q}_{9}$ and $\mathrm{Q}_{10}$ in developing palm fruits. J. Am. Oil Chem. Soc., 86: 201-205. DOI: 10.1007/s11746-009-1345$\mathrm{z}$

Ong, A.S.H., E. Niki and L. Packer, 1995. Nutrition, Lipids, Health and Disease. 1st Edn., AOCS Press, USA., ISBN-10: 0935315640, pp: 374.

Sambanthamurthi, R., Y.A. Tan and K.S. Manickam, 1998. Treatment of vegetation liquors derived from oil bearing fruits.

Sambanthamurthi, R., Y.A. Tan, K.S. Manickam and M.B. Wahid, 2007. Botanical extracts from oil palm vegetation liquor for cosmeceutical application.

Singleton, V.L. and J.A. Rossi Jr., 1965. Colorimetry of total phenolics with phosphomolybdicphosphotungstic acid reagents. Am. J. Ecol. Vitic., 16: 144-158.

Sundram, K., R. Sambanthamurthi and Y.A. Tan, 2003. Palm fruit chemistry and nutrition. Asia Pacific J. Clin. Nutr., 3: 355-362. PMID: 14506001

Thaipong, K., U. Boonprakob, K. Crosby, L. CisnerosZevallos and D.H. Byrne, 2006. Comparison of ABTS, DPPH, FRAP and ORAC assays for estimating antioxidant activity from guava fruit extracts. J. Food Comp. Anal., 19: 669-675.

Wang, H. and K. Helliwell, 2001. Determination of flavonols in green and black tea leaves and green tea infusions by high-performance liquid chromatography. Food Res. Int., 34: 223-227. DOI: 10.1016/S0963-9969(00)00156-3

Yen, G.C. and P.D. Duh, 1994. Scavenging effect of methanolic extracts of peanut hulls on free-radical and active-oxygen species. J. Agric. Food Chem., 42: 629-632. DOI: 10.1021/jf00039a005 